Research Article

\title{
The Behavior of a Coarse Granular Material under Complex Stress Conditions
}

\author{
Yuefeng Zhou (D), Jiajun Pan, Zhanlin Cheng, and Yongzhen Zuo \\ Key Laboratory of Geotechnical Mechanics and Engineering of Ministry of Water Resources, \\ Changjiang River Scientific Research Institute, Wuhan 430010, China
}

Correspondence should be addressed to Yuefeng Zhou; zhouyuefeng@mail.crsri.cn

Received 9 September 2020; Accepted 7 May 2021; Published 26 May 2021

Academic Editor: Shazim A. Memon

Copyright ( 2021 Yuefeng Zhou et al. This is an open access article distributed under the Creative Commons Attribution License, which permits unrestricted use, distribution, and reproduction in any medium, provided the original work is properly cited.

In recent years, dozens of high rockfill dams are under construction or planning for hydropower exploration in western China. In dam construction, the mechanical behavior of coarse granular material greatly affects the compatible deformation of dam body. In this article, an indirect in situ density prediction approach for coarse granular material is firstly proposed to solve the technical obstacle on prediction of the material density in thick overburden layer of a dam site in southwest China. Adopting a selfdeveloped large-scale true triaxial apparatus with a special friction-reduction technique, four series of true triaxial tests were then performed to investigate the behavior of a coarse granular material with a maximum particle diameter of $60 \mathrm{~mm}$. Test results show that the peak strength of the material increases together with the increasing confining stress and the increasing intermediate principal stress ratio. The material dilatancy is restricted by both the confining stress and the intermediate principal stress ratio. With the increase in intermediate principal stress ratio, the internal friction angle increases firstly and then decreases slightly, but the slope of stress path reduces gradually. The tested peak states were compared with several well-known strength criteria under the framework of generalized stress, showing a good fitness with the Lade-Duncan criterion and underestimation by the Mohr-Coulomb criterion and the Matsuoka-Nakai criterion. The strength envelope in the $\pi$ plane shrinks with the increasing confining stress.

\section{Introduction}

There are abundant clean nonpolluting hydropower resources in western China, including the Yalongjiang River, the Daduhe River, the Lancangjiang River, and the Jinshajiang River. In recent years, dozens of high rockfill dams are under construction or planning on the above rivers for extensive hydropower exploration. In order to achieve appropriately designated internal zones, a rockfill dam is commonly constructed utilizing different materials, which have significantly different stiffness and strength properties. An associated issue in the design of rockfill dam is the compatible deformation of dam body, which should be partially considered for coarse granular material used in construction.

The material could experience different stress paths in engineering construction and impounding periods [1]. In another aspect, the riverbed of rockfill dam is always covered by thick overburden layer from dozens to hundreds of meters, which is commonly composed of coarse granular material, such as sandy gravel and pebble [2]. It can hardly be fully excavated for dam construction and hence affects the dam settlement. Mountainous regions with complicated geological conditions lead to complex stress conditions that need to be considered in engineering design. The behavior of coarse granular material under complex stress conditions is therefore vital towards developing and economizing the engineering design method. Coarse granular material was considered to have intrinsic similar properties with sand as both are cohesionless and composed of mineral aggregates and hence was investigated on an extension of sand behavior [3]. The difference could be attributed to typical particle size of both materials. Size effect leads to distinct physical and mechanical properties in the aspects of compressibility, 
dilatancy, rheology, and breakage and demonstrates different material behaviors.

Most laboratory investigations on the behavior of coarse granular material are based on conventional triaxial tests or plane strain tests [3]. Under in situ stress conditions, a geological element is at a general stress state of unequal principal stresses in three directions. There are three independent stress components necessary to describe the stress state at a certain point in stress space, for example, the principal stress components $\left(\sigma_{1}{ }^{\prime}, \sigma_{2}{ }^{\prime}, \sigma_{3}{ }^{\prime}\right)$, the stress invariants $\left(I_{1}, I_{2}, I_{3}\right)$, the mean/deviator stresses, and Lode angle components $(q, p, \theta)$. In three-dimensional stress space, the onset of material failure is dependent on all three principal stresses. Previous studies have proved that the intermediate principal stress has a great contribution to material strength [4-7]. However, the influence of the intermediate principal stress on material failure has largely been neglected when conducting engineering analyses of geomechanical problems. The popularity of the Mohr-Coulomb criterion is partly led by the limitations of conventional triaxial testing in laboratory. Researchers pay great efforts in the development of true triaxial apparatus with different specimen sizes to study material behavior under complex stress conditions (Table 1), with consideration of scale effect brought by the maximum particle diameter of the tested material. The loading pattern in a true triaxial apparatus can be divided into three types, i.e., rigid loading [8-10], flexible loading [11-14], and mixed loading [1, 15-20].

Strength criteria with three independent stress parameters were proposed, such as Matsuoka-Nakai criterion [5], Lade-Duncan criterion [21], modified Lade-Duncan criterion [22] for soil material, and Mogi criterion and HoekBrown criterion for rock material [23]. Researchers performed true triaxial tests on different materials from clay to sand and discussed issues of shear strength, shear band [4], state parameter [1], and so on. The Matsuoka-Nakai criterion was reported to agree well with the failure points of both overconsolidated and normal consolidated clays [20] and those of Toyora sand [24]. After performing true triaxial tests on granular soil, Shi et al. [25] presented that failure points were between the Lade-Duncan envelope and the Matsuoka-Nakai envelope. Lade et al. [4] further discussed the variation in internal friction angle with intermediate principal stress for different sands. True triaxial tests on rockfill material were also performed for different stress paths to study the strength-dilation behavior of the material [26], whose maximum particle diameter achieves $10 \mathrm{~mm}$. Under relative small deformation, Anhdan et al. [17] evaluated quasi-elastic properties of gravel using a self-developed large-scale true triaxial apparatus with a specimen size of $220 \mathrm{~mm} \times 250 \mathrm{~mm} \times 500 \mathrm{~mm}$.

This article aims to clarify the effect of the intermediate principal stress ratio on the behavior of a coarse granular material with a maximum particle diameter of $60 \mathrm{~mm}$, which so far has not been conferred sufficiently from the experimental points of view.

\section{Materials and Methods}

2.1. Test Material. The test material in this study was obtained from thick overburden layer of a hydropower station in western China, which is adopted as dam construction material as well. As huge particles are utilized in construction, in situ material cannot be tested directly in laboratory with consideration of specimen size. According to specification on soil testing SL237-1999 [27], the particle grading curve in the field was downscaled using the equivalent replacing method and then adopted in laboratory (Figure 1). Basic physical properties of the material were obtained as follows: a minimum dry density of $1.977 \mathrm{~g} / \mathrm{cm}^{3}$, a maximum dry density of 2.307 , a specific gravity of 2.79 , a minimum void ratio of 0.209 , and a maximum void ratio of 0.411 .

Inspection pit and borehole are commonly adopted to determine in situ density of fine grained soils. However, a technical obstacle for coarse granular materials (in the scale of one meter diameter) is that their in situ density with depth of dozens of meters is hard to determine which affects soil behavior significantly. In situ density is important when performing laboratory tests on coarse granular material as it affects material stiffness greatly. In this study, an approximation approach is proposed below. Utilizing material with different grading curves but from the same source, in situ pressuremeter tests and model pressuremeter tests are performed in the field and in laboratory, respectively. When the prototype material and the downscaled material have equal pressuremeter modulus, they could have closed physical properties. According to local ground investigation report, the depth of the material is $22.8-34.4 \mathrm{~m}$, with an average value of $27.4 \mathrm{~m}$. It suggests an effective overburden pressure of $340 \mathrm{kPa}$. Ground investigation report [28] suggests the pressuremeter modulus varies from $31.7 \mathrm{MPa}$ to 42.4 MPa, with an average value of $37.8 \mathrm{MPa}$. Model pressuremeter tests were then conducted in laboratory at five different densities, i.e., $2.10 \mathrm{~g} / \mathrm{cm}^{3}, 2.16 \mathrm{~g} / \mathrm{cm}^{3}, 2.22 \mathrm{~g} / \mathrm{cm}^{3}$, $2.28 \mathrm{~g} / \mathrm{cm}^{3}$, and $2.34 \mathrm{~g} / \mathrm{cm}^{3}$. The relationship between soil density and modulus can then be obtained (Figure 2). Based on above curve, the in situ density is predicted as $2.28 \mathrm{~g} / \mathrm{cm}^{3}$.

Specimens in true triaxial tests were prepared at the controlled density of $2.28 \mathrm{~g} / \mathrm{cm}^{3}$, representing a relative density of 0.875 . A specimen was prepared using the moist tamping technique by five layers. In each layer, different components of granular material (Figure 3) are mixed independently to ensure a relatively uniform composition. The controlled maximum particle diameter in true triaxial tests is $60 \mathrm{~mm}$, with consideration of specimen size in the test apparatus [29].

2.2. Test Apparatus. A large-scale true triaxial apparatus developed by Changjiang River Scientific Research Institute [29] was adopted in this study (Figure 4(a)). The true triaxial apparatus adopts tall quadrilateral specimen with $600 \mathrm{~mm}$ height and $300 \mathrm{~mm} \times 300 \mathrm{~mm}$ equal width in cross section (Figure 5). Both stress-control and strain-control loading 
TABle 1: Summary of some reported true triaxial apparatuses.

\begin{tabular}{|c|c|c|c|}
\hline No. & Organization or designer & Specimen size $/ \mathrm{mm}^{3}$ & Loading pattern \\
\hline 1 & Kjellman W & $62 \times 62 \times 62$ & Rigid \\
\hline 2 & University of Cambridge, UK & $70 \times 70 \times 35$ & Rigid \\
\hline 3 & Nagoya Institute of Technology, Japan & $100 \times 100 \times 100$ & Rigid \\
\hline 4 & University of Surrey, UK & $100 \times 100 \times 100$ & Flexible \\
\hline 5 & Illinois Institute of Technology, USA & $102 \times 102 \times 102$ & Flexible \\
\hline 6 & The University of Tennessee, USA & $102 \times 102 \times 102$ & Flexible \\
\hline 7 & University of Washington, USA & $241 \times 241 \times 241$ & Flexible \\
\hline 8 & Tongji University & $120 \times 70 \times 70$ & Flexible \\
\hline 9 & University of London, UK & $75 \times 75 \times 75$ & Mixed \\
\hline 10 & Japan Seto Corporation & $25.6 \times 88.9 \times 88.9$ & Mixed \\
\hline 11 & Louisiana State University, USA & $60 \times 120 \times 180$ & Mixed \\
\hline 12 & AnhDan & $220 \times 250 \times 500$ & Mixed \\
\hline 13 & The Hong Kong Polytechnic University & $70 \times 70 \times 140$ & Mixed \\
\hline 14 & Hohai University & $120 \times 60 \times 120$ & Mixed \\
\hline 15 & Xi'an University of Technology & $70 \times 70 \times 70$ & Mixed \\
\hline 16 & Shanghai Jiao Tong University & $80 \times 80 \times 50$ & Mixed \\
\hline 17 & Changjiang River Scientific Research Institute & $300 \times 300 \times 600$ & Mixed \\
\hline 18 & GCTS Corporation & $75 \times 75 \times 150$ & Mixed \\
\hline 19 & GDS Corporation & $75 \times 75 \times 150$ & Mixed \\
\hline
\end{tabular}

patterns can be achieved using the apparatus. The true triaxial apparatus adopts a new rigid and flexible mixed loading technique. In the direction of minor principal stress, cell water pressure is applied on the specimen as flexible loading. In the direction of major principal stress, vertical load is applied via rigid plates at the top and the bottom of the specimen. In the direction of intermediate principal stress, lateral load is applied on the specimen via a pair of friction-reduction plates. A friction-reduction plate is composed of $30 \times 60$ blocks, which transfer integral contact into distributed contact. Being underlain by slight ball bearings and grooves, the slide blocks can move laterally and vertically. In the loading process, the local deformation of a specimen occurs with movement of slide blocks. Sliding friction is replaced by rolling friction, leading to a considerable reduction in friction force on the lateral surface of specimen. More details are introduced in the Patent [29]. Adopting the above apparatus, three unequal principal stresses can be applied to the specimen independently.

The true triaxial apparatus includes six sets of loading and measuring devices, each set of which contains a laser displacement transducer, a load transducer, and a hydrocylinder. The internal load cell measures the axial load applied to the specimen. Besides, it includes the following components: a cell pressure transducer, a pore-water pressure transducer, and an outer and an inner volumetric deformation measuring system. A controlling system was designed to implement a certain defined stress path using corresponding algorithms. A data acquisition system was designed to acquire electronic signals and to transfer them into digital data.

2.3. Test Program. When $b=0.0$, the stress path in a true triaxial test should be absolutely the same with that in a conventional triaxial test. To verify the true triaxial apparatus, parallel consolidated and drained tests at $b=0.0$ and

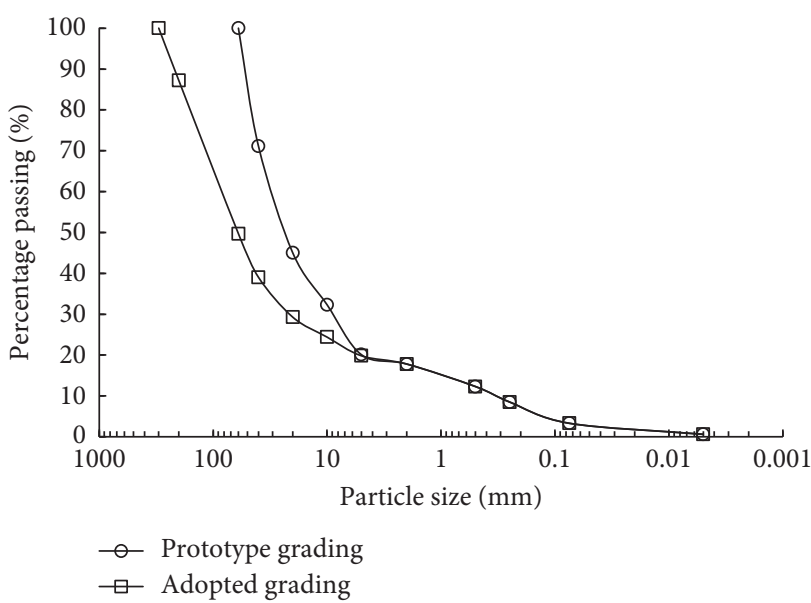

FIGURE 1: The prototype grading curve in the field and the adopted grading curve in laboratory.

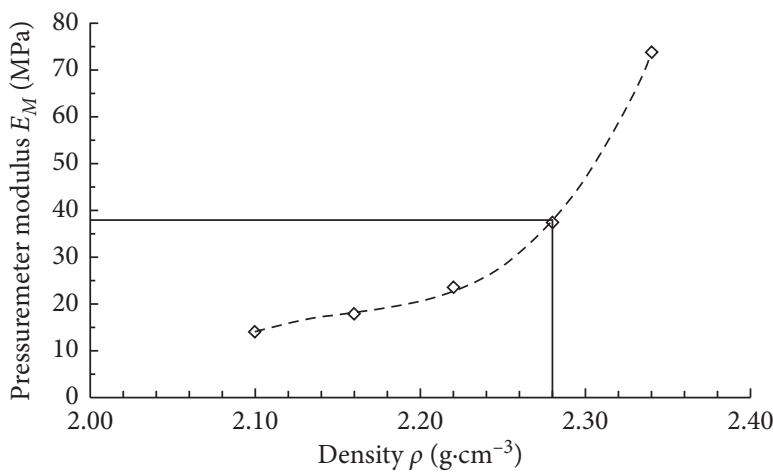

FIgURE 2: Prediction of in situ density based on pressuremeter model tests.

$\sigma_{3}{ }^{\prime}=0.4 \mathrm{MPa}$ were carried out using the large-scale true triaxial apparatus and another conventional large-scale triaxial apparatus, respectively (Figure 4 ). Thereafter, a total 


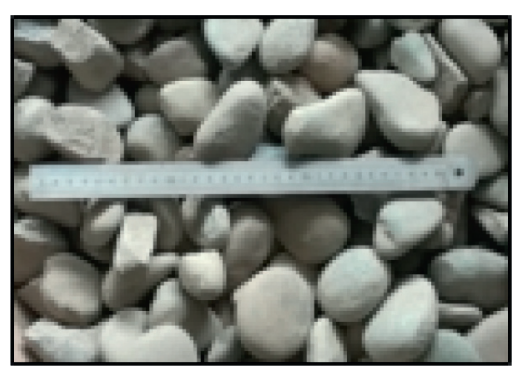

60 40 mm

(a)

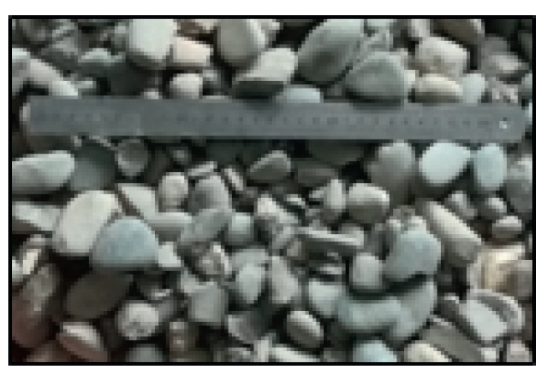

$40 \sim 20 \mathrm{~mm}$

(b)

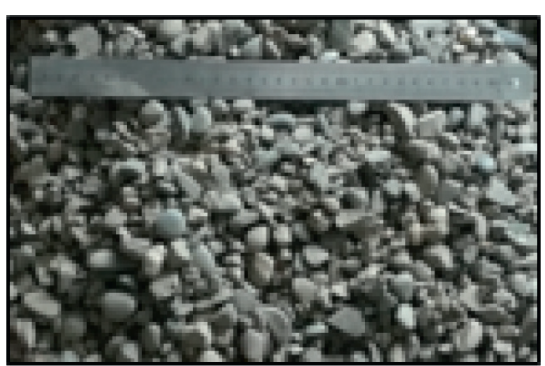

(c)

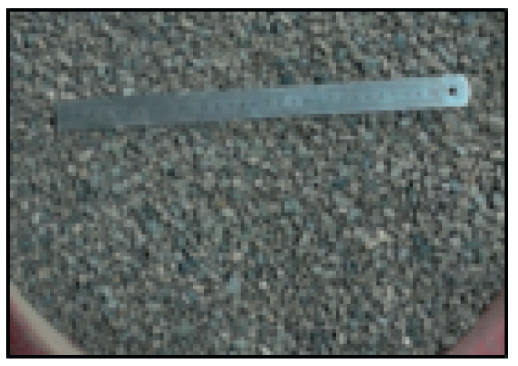

(d)

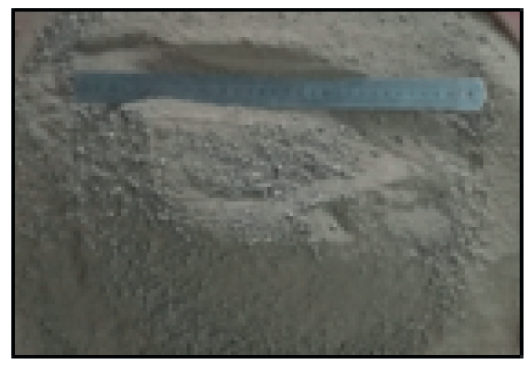

(e)

Figure 3: Sample components.

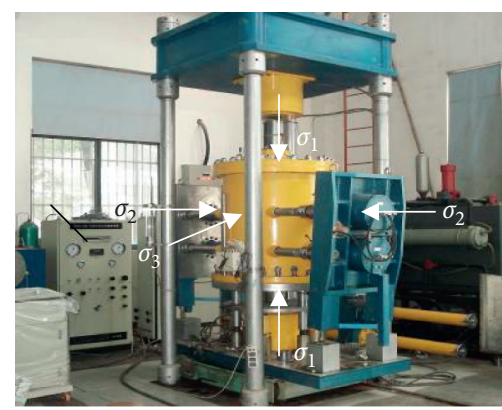

(a)

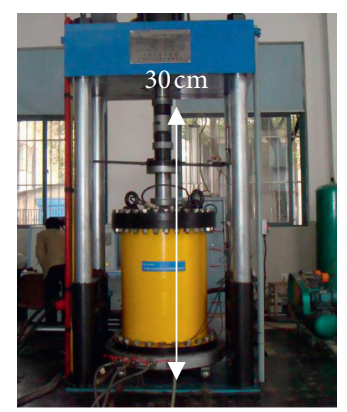

(b)

FIgURE 4: Test apparatus: (a) the true triaxial apparatus; (b) the conventional triaxial apparatus

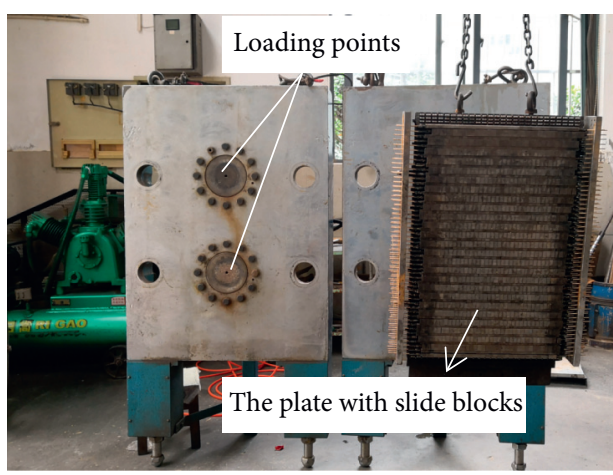

(a)

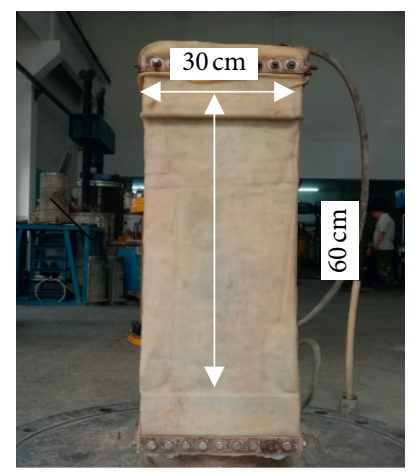

(b)

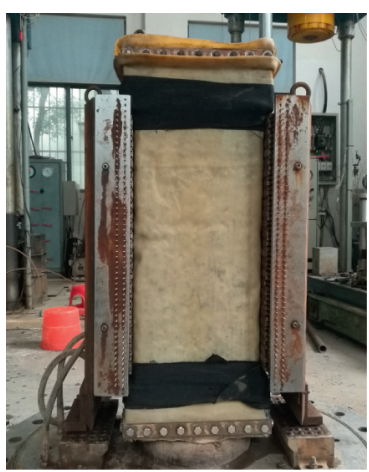

(c)

FIGURE 5: Specimen and setup of lateral plates: (a) friction-reduction plate; (b) specimen in the true triaxial test; (c) installation of internal lateral plates. 
of four series of true triaxial tests (25 tests, as shown in Table 2) were performed to investigate the influences of intermediate principal stresses and isotropic consolidation pressure. Among them, three series were conducted on specimens at different values of the intermediate principal stress ratio $b$, which is defined as follows:

$$
b=\frac{\left(\sigma_{2}^{\prime}-\sigma_{3}^{\prime}\right)}{\left(\sigma_{1}^{\prime}-\sigma_{3}^{\prime}\right)}
$$

where $\sigma_{1}{ }^{\prime}, \sigma_{2}{ }^{\prime}$, and $\sigma_{3}$ ' are the major, intermediate, and minor principal stresses, respectively.

The first and second series of true triaxial tests (at the initial isotropic consolidation pressures $\sigma_{3}{ }^{\prime}=0.2 \mathrm{MPa}$ and $0.4 \mathrm{MPa}$, respectively) were performed under nine different $b$ values, i.e., $b=0,0.15,0.25,0.375,0.50,0.625,0.75,0.875$, and 1.00. As the rubber membrane is easy to be punctured at higher stress condition, the third series (at the initial isotropic consolidation pressure $\sigma_{3}{ }^{\prime}=0.8 \mathrm{MPa}$ ) was performed only at four different $b$ values, i.e., $b=0.00,0.25,0.50$, and 0.75. The fourth series tests were performed under plane strain condition at three different isotropic consolidation pressures, i.e., $\sigma_{3}{ }^{\prime}=0.2 \mathrm{MPa}, 0.4 \mathrm{MPa}$, and $0.8 \mathrm{MPa}$. All of the tests were carried out under consolidated and drained conditions.

Prior to a test, a pore-water pressure coefficient $(B)$ of 0.95 needs to be achieved. For this purpose, a specimen was saturated by applying suction and flushing water from its bottom, followed by gradually increasing cell pressure and back pressure. The axial strain was increased at a rate of $0.33 \% / \mathrm{min}$ for drained loading tests on the saturated material. In the testing process, the volumetric strain was calculated using the volume of discharged water from the specimen utilizing the inner volumetric deformation measuring system.

\section{Results and Analyses}

Under general stress condition, the mean effective stress $p^{\prime}$ and the deviator stress $q$ are defined to satisfy the principle of work-energy conservation as follows:

$$
\begin{aligned}
p^{\prime} & =\frac{\left(\sigma_{1}^{\prime}+\sigma_{2}^{\prime}+\sigma_{3}^{\prime}\right)}{3}, \\
q & =\left\{\frac{\left[\left(\sigma_{1}^{\prime}-\sigma_{2}^{\prime}\right)^{2}+\left(\sigma_{1}^{\prime}-\sigma_{3}^{\prime}\right)^{2}+\left(\sigma_{2}^{\prime}-\sigma_{3}^{\prime}\right)^{2}\right]}{2}\right\}^{1 / 2} .
\end{aligned}
$$

3.1. Verification of the Test Apparatus. Two parallel consolidated and drained tests under $0.4 \mathrm{MPa}$ confining pressure were performed using the true triaxial apparatus (Figure 4(a)) with a tall quadrilateral specimen of $300 \mathrm{~mm} \times 300 \mathrm{~mm} \times 600 \mathrm{~mm}$ and the conventional triaxial apparatus (Figure 4(b)) with a column specimen $\phi$ of $300 \mathrm{~mm} \times 600 \mathrm{~mm}$, respectively. Both stress-strain curves (Figure 6) are very close with consistent stiffness and mobilized strength, suggesting the true triaxial apparatus is relative reliable. Figure 7 shows the postfailure specimen with bulged feature and obvious failure plane in the above true triaxial test.

3.2. The Constant $\sigma_{3}$ and Constant $b$ Tests. Figure 8 presents the variation of the deviator stress with the axial strain under an initial confining pressure $\sigma_{3}{ }^{\prime}=0.2 \mathrm{MPa}$ but at nine different intermediate principal stress ratios, i.e., $b=0.00,0.15$, $0.25,0.375,0.50,0.625,0.75,0.875$, and 1.00 . For all specimens, the deviator stress rises steadily with the increasing axial strain and finally reaches or approaches a peak value. Despite the initial slopes of the stress-strain curves are very close, a specimen at a higher $b$ value commonly achieves a greater peak strength under the same confining pressure. All specimens demonstrate initial contractive deformation, followed by consistent dilation. A higher $b$ value always indicates greater contraction followed by smaller dilation. The maximum volumetric strain increases with increasing $b$ value as well. At a higher $b$ value, a specimen needs greater axial strain to attain a higher maximum volumetric strain.

The behavior of the coarse granular material with respect to $b$ value was further investigated under initial confining pressures $\sigma_{3}{ }^{\prime}=0.4 \mathrm{MPa}$ and $0.8 \mathrm{MPa}$. The test results demonstrate essentially similar phenomena with that under $\sigma_{3}^{\prime}=0.2 \mathrm{MPa}$.

At the $b$ value of 0.75 , the stress-strain relationship of the material under different confining pressures is further plotted and compared in Figure 9. The deviator stress increases monotonically with axial strain and approaches a peak value in the three tests. A higher confining pressure indicates a greater peak strength and a higher initial slope which represents a higher material stiffness. Under the initial confining pressure $\sigma_{3}=0.2 \mathrm{MPa}$, the specimen demonstrated initial obvious contraction followed by slight dilation. Under the initial confining pressures $\sigma_{3}{ }^{\prime}=0.4 \mathrm{MPa}$ and $0.8 \mathrm{MPa}$, specimens showed consistent contraction. Specimens tended to reach stable volumetric strains in all three tests.

3.3. The Plane Strain Tests. In the plane strain tests, all specimens display unanimous strain-hardening behavior under different stress conditions (Figure 10). When subject to drained loading, the deviator stress first rises noticeably when the axial strain is below $1 \%$. It then enhances in a much slower rate and achieves or approaches a peak strength at the termination of test. For the tests $\sigma_{3}{ }^{\prime}=0.2 \mathrm{MPa}$ and $\sigma_{3}{ }^{\prime}=0.4 \mathrm{MPa}$, the volumetric strain increases initially and reaches peak values at $2 \%$ and $5 \%$ axial strain and then decreases in different degrees gradually, reflecting a process of initial contraction followed by dilation. For the test $\sigma_{3}{ }^{\prime}=0.8 \mathrm{MPa}$, the specimen displays continuous contractive deformation in the whole loading process. The above volumetric behavior implies that the dilative deformation is depressed by the increasing confining pressure $\sigma_{3}$. In the plane strain tests, after initial holding at zero, the intermediate principal stress ratio $b$ increases consistently with axial strain. For the tests $\sigma_{3}{ }^{\prime}=0.2 \mathrm{MPa}, \sigma_{3}{ }^{\prime}=0.4 \mathrm{MPa}$, and $\sigma_{3}{ }^{\prime}=0.8 \mathrm{MPa}$, the final $b$ values are $0.20,0.17$, and 0.15 , respectively, indicating that the increase in $b$ value is depressed by the increasing confining pressure. 
TABLE 2: Test program and corresponding peak states.

\begin{tabular}{|c|c|c|c|c|c|c|c|c|}
\hline \multirow{2}{*}{ Test } & \multirow{2}{*}{$b$ value } & \multirow{2}{*}{ Lode angle } & \multicolumn{2}{|c|}{$\sigma_{3}=200 \mathrm{kPa}$} & \multicolumn{2}{|c|}{$\sigma_{3}=400 \mathrm{kPa}$} & \multicolumn{2}{|c|}{$\sigma_{3}=800 \mathrm{kPa}$} \\
\hline & & & $p / \mathrm{MPa}$ & $q / \mathrm{MPa}$ & $p / \mathrm{MPa}$ & $q / \mathrm{MPa}$ & $p / \mathrm{MPa}$ & $q / \mathrm{MPa}$ \\
\hline \multirow{9}{*}{ Constant $\sigma_{3}$ and constant $b$ tests } & 0.00 & -30 & 0.556 & 1.067 & 0.952 & 1.655 & 1.826 & 3.078 \\
\hline & 0.150 & -22.0 & 0.706 & 1.183 & 1.188 & 1.901 & - & - \\
\hline & 0.25 & -16.1 & 0.827 & 1.293 & 1.425 & 2.180 & 2.506 & 3.681 \\
\hline & 0.375 & -7.9 & 0.965 & 1.458 & 1.706 & 2.480 & - & - \\
\hline & 0.50 & 0 & 1.106 & 1.574 & 1.961 & 2.710 & 3.414 & 4.524 \\
\hline & 0.625 & 8.5 & 1.292 & 1.764 & 2.284 & 3.044 & - & - \\
\hline & 0.75 & 16.1 & 1.431 & 1.900 & 2.529 & 3.283 & 4.037 & 4.998 \\
\hline & 0.875 & 23.7 & 1.889 & 2.547 & 2.628 & 3.363 & - & - \\
\hline & 1.00 & 30 & 1.987 & 2.681 & 2.732 & 3.498 & - & - \\
\hline Plane strain tests & - & - & 0.749 & 1.260 & 1.264 & 2.057 & 2.287 & 3.637 \\
\hline
\end{tabular}

Taking the test $\sigma_{3}{ }^{\prime}=0.8 \mathrm{MPa}$ as an example, the stressstrain curve is located between corresponding curves in the constant $\sigma_{3}^{\prime}$ and constant $b$ tests at $b=0.0$ and $b=0.25$, representing the upper limit and lower limit of $b$ values in the plane strain tests. The peak strength in the plane strain tests is close to that in the constant $\sigma_{3}$ ' and constant $b$ tests when $b=0.25$. Similarly, the specimen in the plane strain test shows more obvious increase in deviator stress after $4 \%$ axial strain than that in the constant $\sigma_{3}$ and constant $b$ tests (Figure 11). As mentioned previously, a specimen at higher $b$ value displays higher shear strength. The rising $b$ value herein suggests an increasing mobilized strength as well.

\section{Discussion}

4.1. Stress Path and Strength Analyses. In the constant $\sigma_{3}$ ' and constant $b$ tests and the plane strain tests, the confining stress $\sigma_{3}$ satisfies the following:

$$
\mathrm{d} \sigma_{3}^{\prime}=0 .
$$

Substituting equation (3) into equations (2a) and (2b), we can obtain the following equation:

$$
f=\frac{\mathrm{d} q}{\mathrm{~d} p^{\prime}}=3 \sqrt{\frac{\left(b^{2}-b+1\right)}{(b+1)}} .
$$

Equation (4) defines a decreasing function of $b$ value within the range $b=[0,1]$ and suggests that the slope of a stress path decreases with increasing $b$ value.

Under the same confining pressure $\sigma_{3}{ }^{\prime}$, the slope of stress path reduces together with $b$ value but achieves higher deviator stress at greater $b$ value (Figure 8(c)). At the same $b$ value, the stress state moves upper right continuously under different confining stresses and demonstrates parallel stress paths at the same $b$ value (e.g., $b=0.75$ in Figure 9(c)).

In the plane strain tests, $b$ value increases continuously in the loading process in all three tests. Correspondingly, the slope of the stress path decreases gradually, demonstrating downward bending curves (Figure 10(c)). Both in the constant $\sigma_{3}{ }^{\prime}$ and constant $b$ tests and in the plane strain tests, the tested stress paths show consistent trend with equation (4).

The stress states at peak strength in the constant $\sigma_{3}{ }^{\prime}$ and constant $b$ tests are plotted together in Figure 12. Generally,

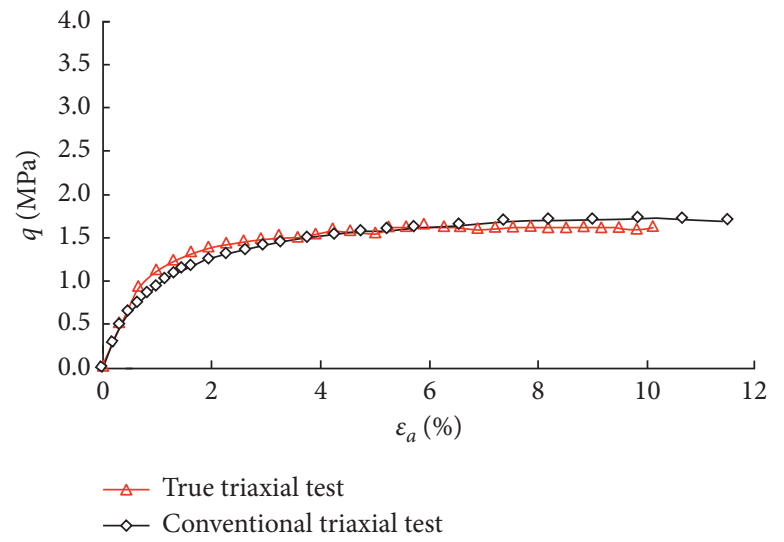

FIgURE 6: Comparative analyses of stress-strain curves at $\sigma_{3}=0.4 \mathrm{MPa}$ in the true triaxial test and in the conventional triaxial test.

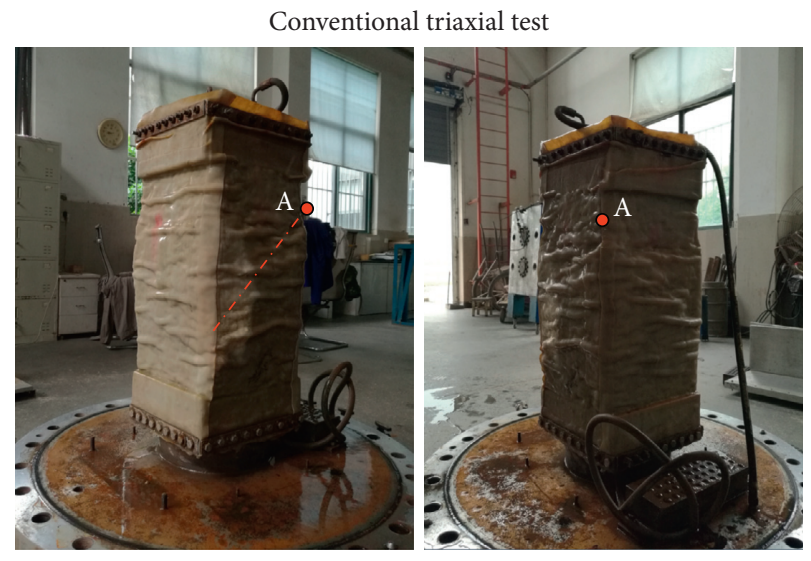

Figure 7: Typical failure state in true triaxial tests.

a linear best-fitted $q: p$ relationship can be obtained at $b=0.00,0.25,0.50$, and 0.75 . A common trend is the peak state stress ratio decreases continuously with the increase in $b$ value, suggesting that the mobilized strength decreases under unit mean effective stress.

4.2. Strength Parameters. At $b=0.00,0.25,0.50$, and 0.75 , Mohr circles of the material under three different confining pressures are plotted in Figure 13. The Mohr circles are well 


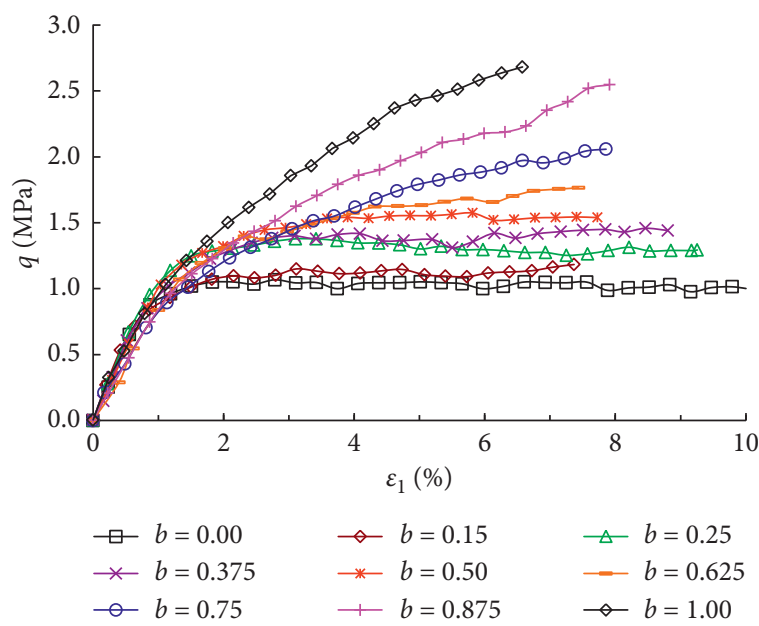

(a)

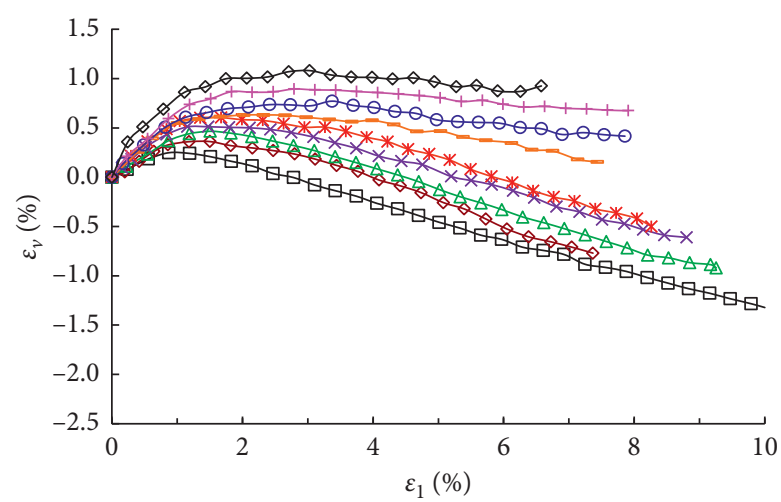

$$
\begin{aligned}
& \square-b=0.00 \\
& \multimap b=0.15 \\
& \text { * } b=0.50 \\
& \triangle \quad b=0.25 \\
& \times b=0.375 \\
& -b=0.875 \\
& -b=0.625 \\
& \multimap b=1.00
\end{aligned}
$$

(b)

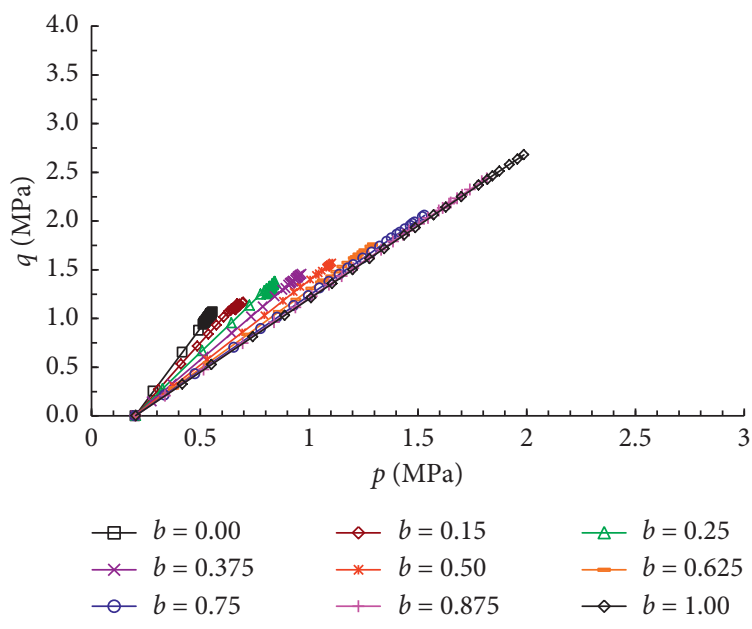

(c)

Figure 8: The results of the constant $\sigma_{3}$ and constant $b$ tests at $\sigma_{3}=0.2 \mathrm{MPa}$ : (a) stress-strain curves; (b) volumetric strain curves; (c) stress paths.
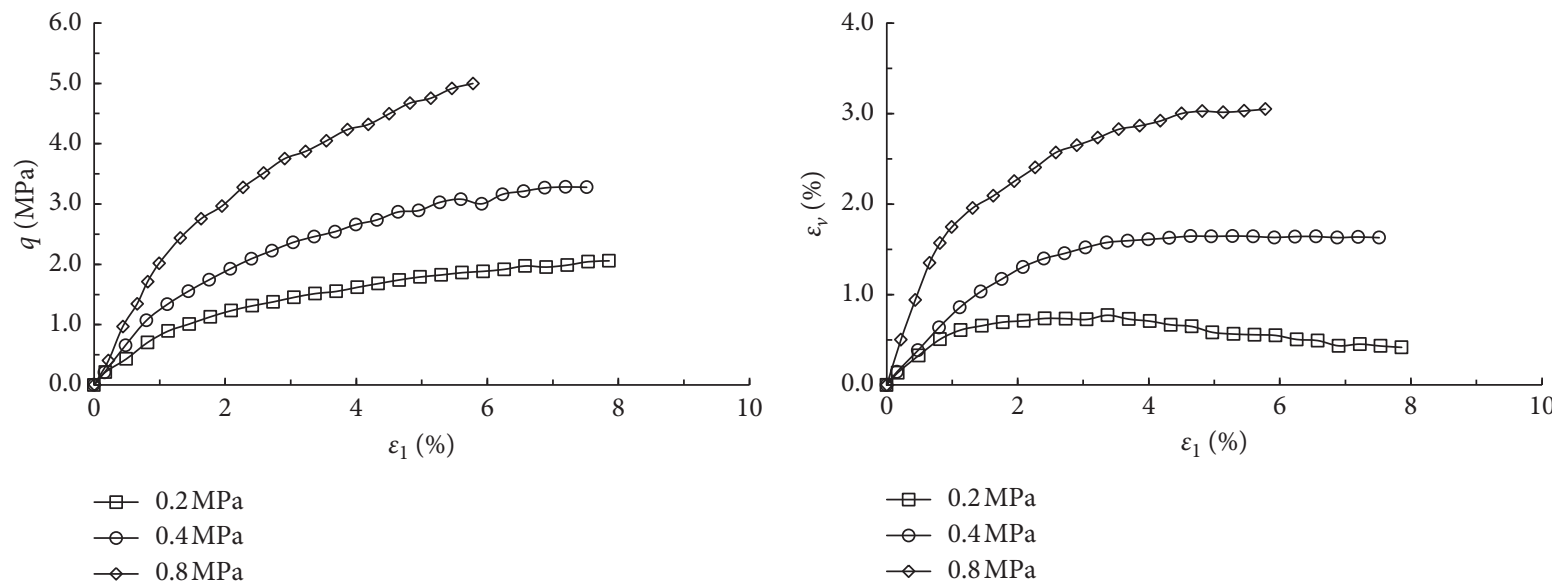

(a)

(b)

Figure 9: Continued. 


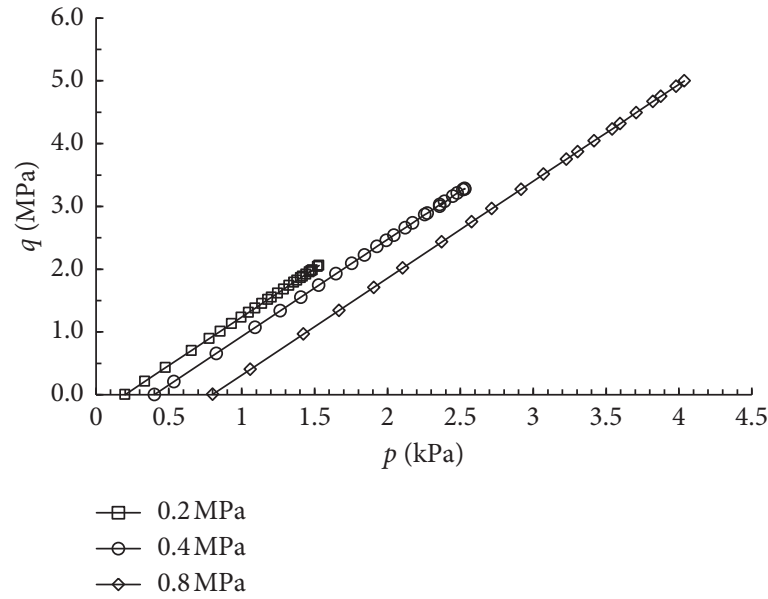

(c)

Figure 9: Comparison on the constant $\sigma_{3}$ and constant $b$ tests at $b=0.75$ : (a) stress-strain curves; (b) volumetric strain curves; (c) stress paths.

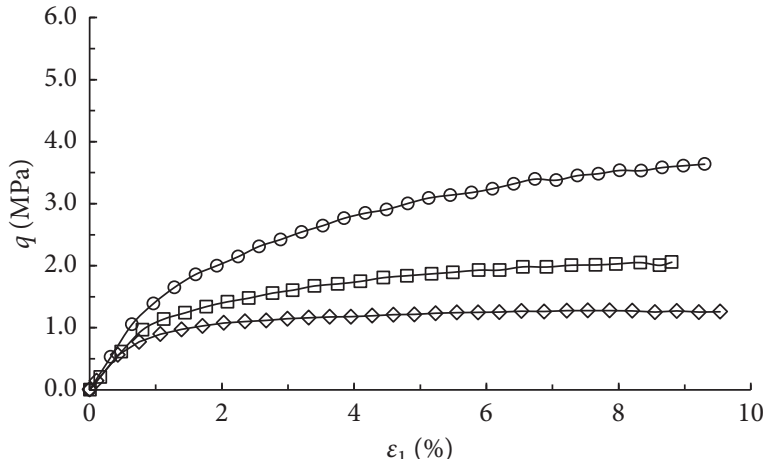

$\diamond 0.2 \mathrm{MPa}$

$\square 0.4 \mathrm{MPa}$

- $0.8 \mathrm{MPa}$

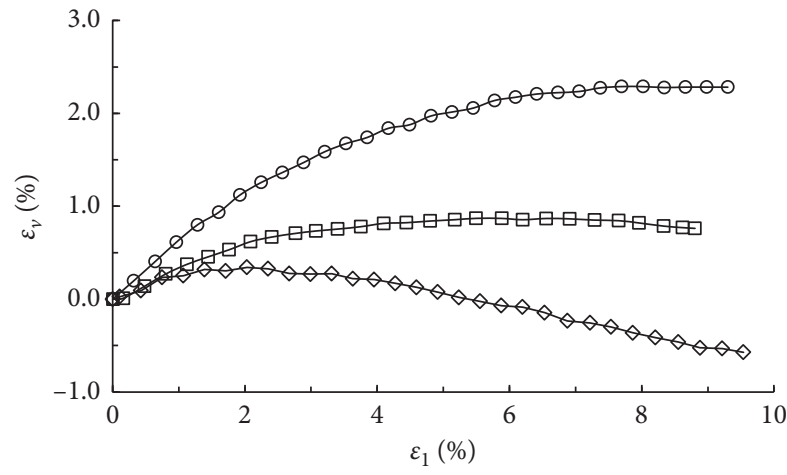

$\begin{array}{ll}\triangleleft & 0.2 \mathrm{MPa} \\ \square & 0.4 \mathrm{MPa}\end{array}$

(a)

(b)

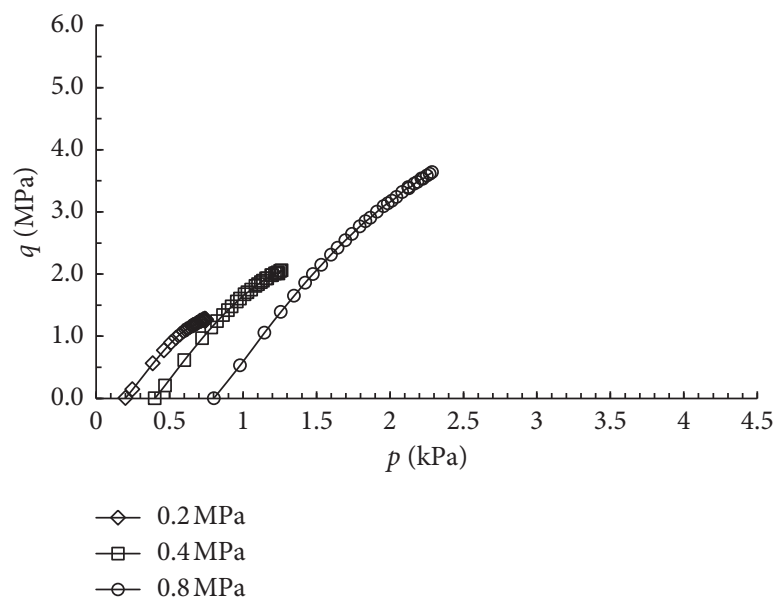

(c)

Figure 10: The results of the plane strain test: (a) stress-strain curves; (b) volumetric strain curves; (c) stress paths. 


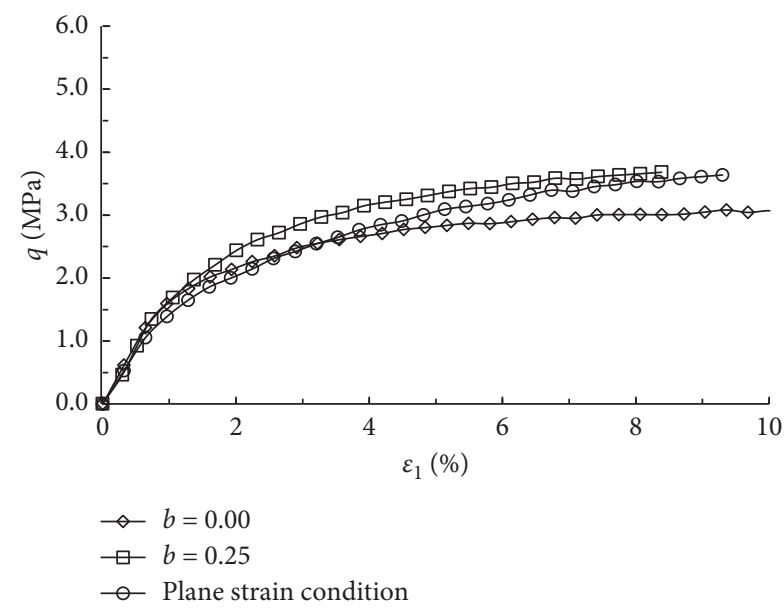

Figure 11: Comparison on the constant $\sigma_{3}$ and constant $b$ test and the plane strain test $\left(\sigma_{3}=0.4 \mathrm{MPa}\right)$.

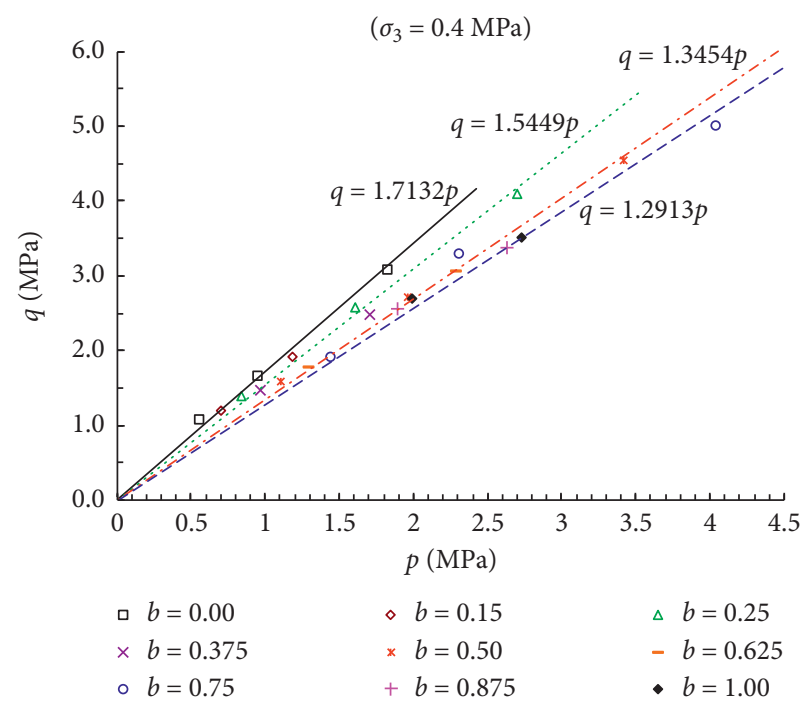

Figure 12: Summary of peak states in different true triaxial tests.

fitted by linear strength envelopes. With the increase in $b$ value, the internal friction angle increases from $39^{\circ}$ to $49.5^{\circ}$ and the apparent cohesion increases from $0.083 \mathrm{MPa}$ to $0.169 \mathrm{MPa}$ (Table 3). Despite the coarse granular material demonstrates apparent cohesion in a certain degree due to granular embedding effect, a common sense is that the coarse granular material should be cohesionless.

Under higher confining stress, the material could experience particle movement, particle breakage, and stress redistribution and leads to reduction in the internal friction angle. To reflect the reduction in internal friction angle with the confining stress, Duncan et al. [30] proposed a nonlinear equation in a logarithmic relationship:

$$
\phi^{\prime}=\phi_{0}^{\prime}-\Delta \phi \log \left(\frac{\sigma_{3}^{\prime}}{P_{a}^{\prime}}\right),
$$

where $p_{\mathrm{a}}{ }^{\prime}$ is the atmospheric pressure; $\varphi_{0}{ }^{\prime}$ is the initial internal friction angle when the confining stress is equal to the atmospheric pressure; and $\Delta \varphi^{\prime}$ is the incremental internal friction angle.

The nonlinear fitted strength envelopes following equation (5) at different $b$ values pass the origin in the $\sigma^{\prime}-\tau$ plane and demonstrates obvious curved feature (Figure 14). Within the range of $b=[0,0.75]$, the initial internal friction angle increases from $48.7^{\circ}$ to $60.8^{\circ}$ and the incremental internal friction angle increases from $8.7^{\circ}$ to $10.8^{\circ}$ (Table 3). The increase in strength parameters from both the linear and the nonlinear strength envelopes could be brought by enhancing lateral restriction together with further particle interlocking.

The calculated values of the internal friction angle using an independent Mohr circle are further compared with those of cohesionless soils from other researchers $[4,14,21,31,32]$ to investigate the influence of intermediate principal stress on the internal friction angle, as such large-scale true triaxial tests on coarse granular materials are seldom introduced. In some reported findings, the internal friction angle increases together with the intermediate principal stress ratio from $b=0$ to $b=0.3$ and then maintains roughly stable with slight fluctuation (Figure 15). In this study, the internal friction angle increases together with the intermediate principal stress ratio from 0 to around 0.75 , then maintains roughly stable, and thereafter demonstrates a slight decrease when $b$ value approaches unit.

4.3. Strength Criteria in the $\pi$ Plane. The strength criterion can be divided into linear and nonlinear types. The linear strength criterion is generally an irregular or regular hexagon in the $\pi$ plane, including Tresca criterion and Mohr-Coulomb criterion. The nonlinear strength criterion should have common features of convexity and smooth continuity, such as Mises criterion, Lade-Duncan criterion, and Matsuoka-Nakai criterion. Some well-known criteria for granular material are briefly introduced as follows.

When material cohesion is zero, the Mohr-Coulomb criterion can be written as follows:

$$
\sin \varphi^{\prime}=\frac{\left(\sigma_{1}^{\prime}-\sigma_{3}^{\prime}\right)}{\left(\sigma_{1}^{\prime}+\sigma_{3}^{\prime}\right)}
$$

After stress space transformation, the equation can be expressed as follows:

$$
6 \sqrt{1-b+b^{2}} \sin \varphi^{\prime} \cdot p^{\prime}-\left[3-(1-2 b) \sin \varphi^{\prime}\right] \cdot q=0 .
$$

The Lade-Duncan criterion [21] can be presented as follows:

$$
\frac{I_{1}^{3}}{I_{3}}=k_{f 1}
$$

where $k_{f 1}$ is a material constant, which could be determined from the internal friction angle $\varphi_{0}$ in conventional triaxial compression tests:

$$
k_{f 1}=\frac{\left(3-\sin \varphi^{\prime}\right)^{3}}{\left[\left(1+\sin \varphi^{\prime}\right)\left(1-\sin \varphi^{\prime}\right)^{2}\right]} .
$$




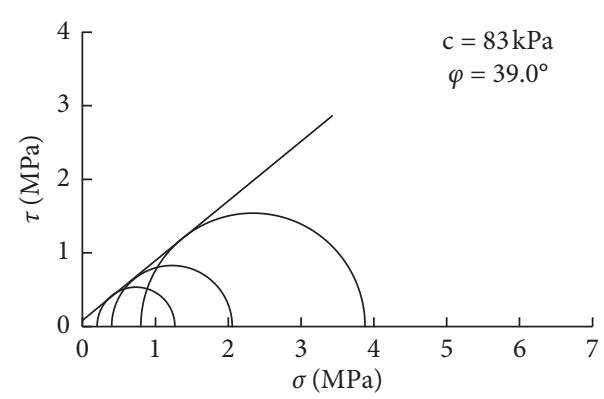

(a)

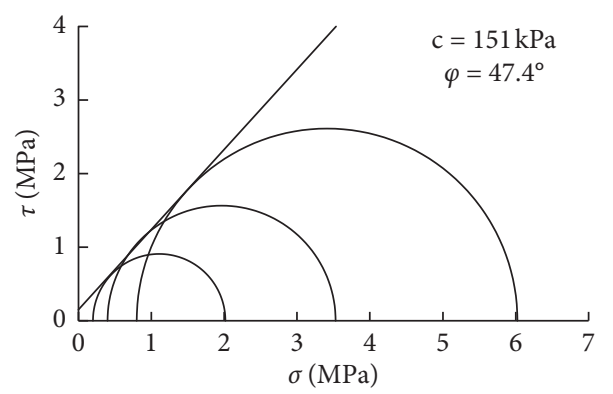

(c)

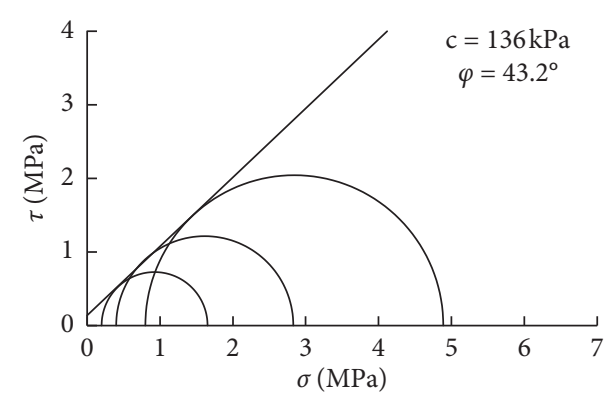

(b)

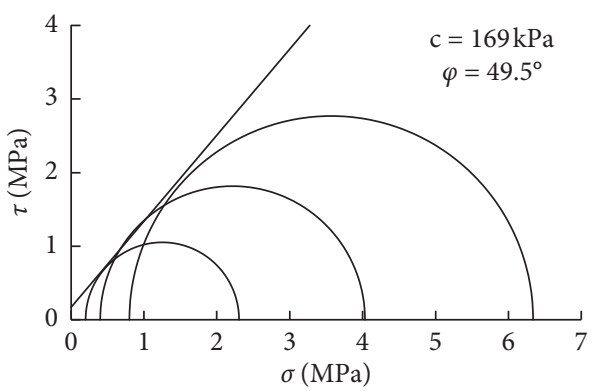

(d)

FIGURE 13: Linear strength envelopes of the coarse granular material at different b values: (a) $b=0.0 ;$ (b) $b=0.25$; (c) $b=0.50$; (d) $b=0.75$.

After stress space transformation, equation (7a) can be deduced as follows:

$$
\begin{aligned}
27 p^{\prime 3}-k_{f 1} & {\left[p^{\prime}+\frac{(2-b) q}{3 \sqrt{b^{2}-b+1}}\right]\left[p^{\prime}+\frac{(2 b-1) q}{3 \sqrt{b^{2}-b+1}}\right] } \\
& {\left[p^{\prime}+\frac{(1+b) q}{3 \sqrt{b^{2}-b+1}}\right]=0 . }
\end{aligned}
$$

The Matsuoka-Nakai criterion [5] can be expressed as follows:

$$
\frac{I_{1} I_{2}}{I_{3}}=k_{f 2},
$$

where $k_{f 2}$ is a material constant, which could be determined from the internal friction angle $\varphi_{0}$ in conventional triaxial compression tests.

$$
k_{f 2}=8 \tan ^{2} \varphi^{\prime}+9
$$

After stress space transformation, equation (8a) can be rewritten as follows:

$$
\begin{gathered}
9 p^{\prime 3}-p^{\prime} q^{2}-k_{f 2}\left[p^{\prime}+\frac{(2-b) q}{3 \sqrt{b^{2}-b+1}}\right]\left[p^{\prime}+\frac{(2 b-1) q}{3 \sqrt{b^{2}-b+1}}\right] \\
{\left[p^{\prime}+\frac{(1+b) q}{3 \sqrt{b^{2}-b+1}}\right]=0 .}
\end{gathered}
$$

TABLE 3: Strength parameters at different $b$ values.

\begin{tabular}{lcccc}
\hline$b$ value & $b=0.00$ & $b=0.25$ & $b=0.50$ & $b=0.75$ \\
\hline$\varphi /^{\circ}$ & 39.0 & 43.2 & 47.4 & 49.5 \\
$\mathrm{c} / \mathrm{MPa}$ & 0.083 & 0.136 & 0.151 & 0.169 \\
$\varphi_{0} /^{\circ}$ & 48.7 & 54.5 & 58.7 & 60.8 \\
$\Delta \varphi /^{\circ}$ & 8.7 & 9.5 & 10.0 & 10.8 \\
\hline
\end{tabular}

The Lode angle $\theta$ is often employed to evaluate the shapes of strength criteria in the $\pi$ plane. It can be defined as a function of the intermediate principal stress ratio $b$ :

$$
\tan \theta=\frac{(2 b-1)}{\sqrt{3}}
$$

where $\theta$ monotonically increases from $\theta=-30^{\circ}$ to $\theta=30^{\circ}$ as $b$ value increases from $b=0$ to $b=1.0$.

Under confining stresses $\sigma_{3}{ }^{\prime}=0.2 \mathrm{MPa}, 0.4 \mathrm{MPa}$, and $0.8 \mathrm{MPa}$, the tested stress states at peak strength are normalized using mean stress $p$ and plotted in the $\pi$ plane using Lode angle. Similarly, the strength envelopes of Lade-Duncan criterion, Matsuoka-Nakai criterion, and Mohr-Coulomb criterion are normalized and shown together in Figure 16 under different confining stresses. For the coarse granular material, the strength points from true triaxial tests are commonly best-fitted by the Lade-Duncan envelope, which lies outside the Matsuoka-Nakai envelope and the Mohr-Coulomb envelope. The Lade-Duncan envelopes normalized at three different confining stresses display shrinkage feature (Figure 16(d)). The coordinate at 


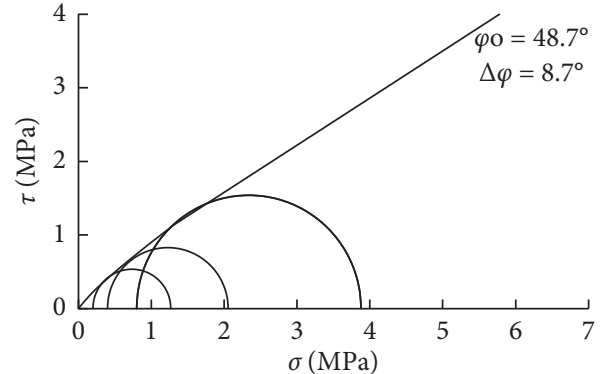

(a)

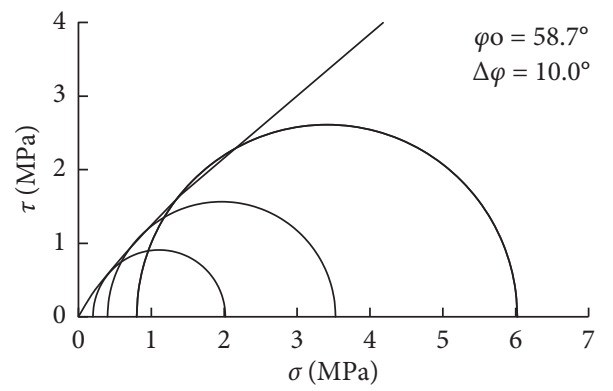

(c)

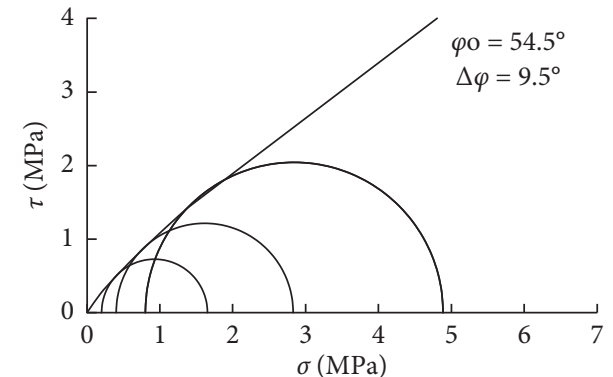

(b)

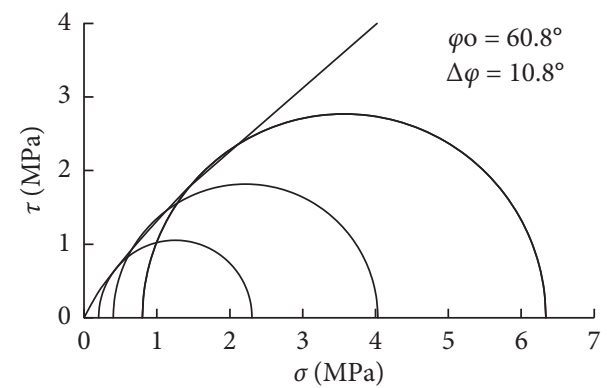

(d)

FigURE 14: Nonlinear strength envelopes of the coarse granular material at different b values: (a) $b=0.0 ;$ (b) $b=0.25$; (c) $b=0.50$; (d) $b=0.75$.

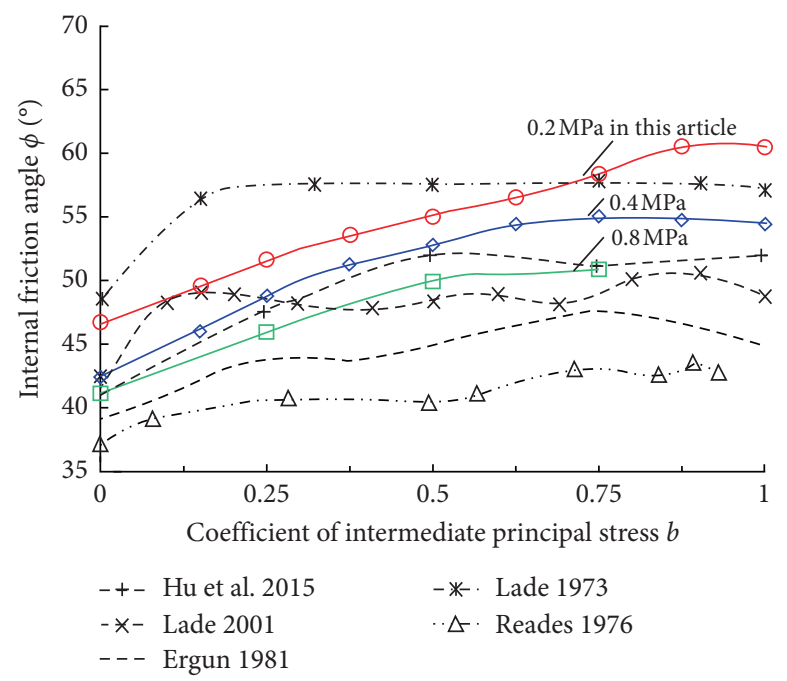

Figure 15: Comparative analyses on the tested internal friction angles. 


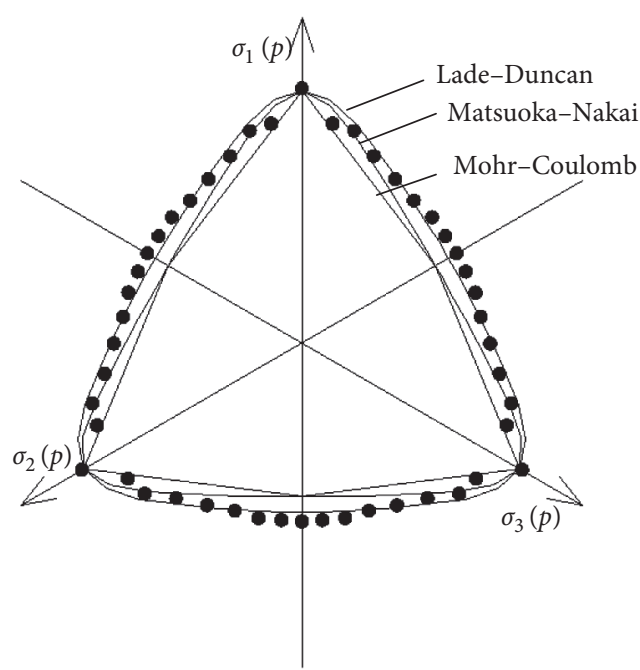

(a)

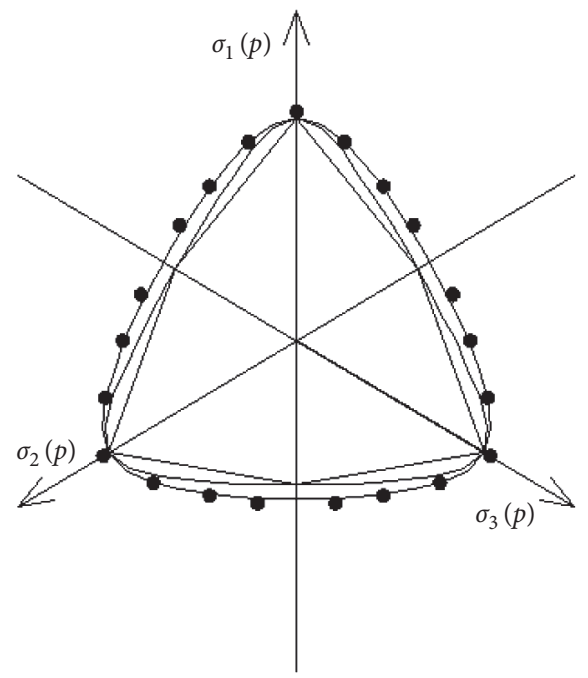

(c)

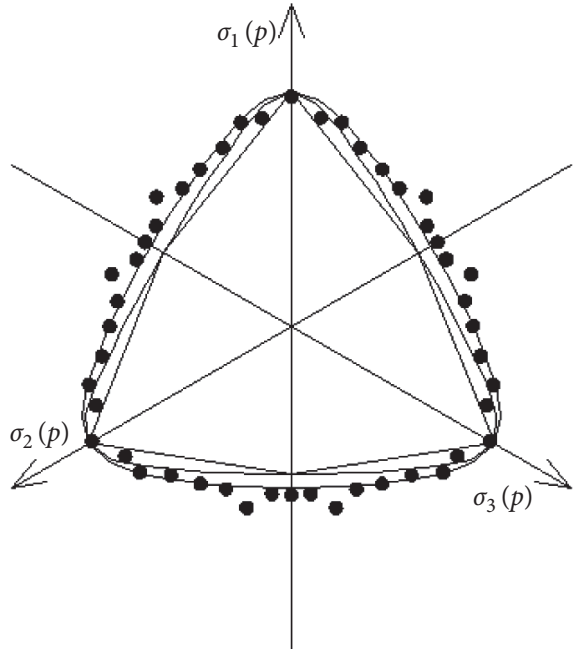

(b)

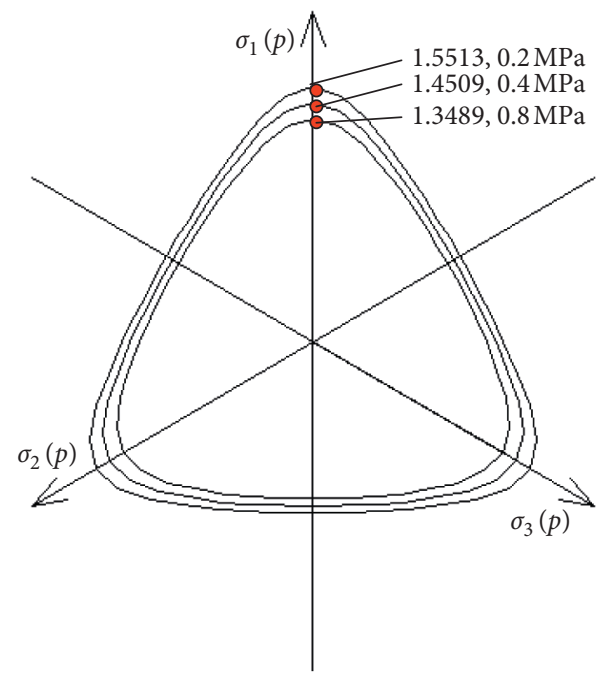

(d)

Figure 16: The failure states in the $\pi$ plane and the envelopes of strength criteria: (a) $\sigma_{3}=0.2 \mathrm{MPa}$; (b) $\sigma_{3}=0.4 \mathrm{MPa}$; (c) $\sigma_{3}=0.8 \mathrm{MPa}$; (d) Lade-Duncan envelopes under different confining stresses.

the intersecting point of the $\sigma_{1}$ axis and the Lade-Duncan envelope reduces from 1.5531 to 1.3489 .

\section{Conclusions}

(1) An equivalent density prediction approach is proposed to solve the technical obstacle on prediction of in situ density of coarse granular material in thick overburden layer. Using downscaled material from the same source of the prototype material, model pressuremeter tests need to be performed in laboratory to build a relationship between the pressuremeter modulus and density. In situ pressuremeter modulus is then projected on the curve to obtain the corresponding in situ density. In this study, the predicted in situ density of the material is $2.28 \mathrm{~g} / \mathrm{cm}^{3}$.

(2) Adopting a self-developed large-scale true triaxial apparatus with a special friction-reduction technique, the behavior of a coarse granular material with the maximum diameter of $60 \mathrm{~mm}$ was investigated following four series of true triaxial tests. The peak strength of the material increases together with the increasing confining stress and the increasing intermediate principal stress ratio. The material dilatancy is affected by the confining stress and the intermediate principal stress ratio.

(3) The slope of the stress path in $q: p^{\prime}$ form reduces with increasing $b$ value when $\sigma_{3}{ }^{\prime}$ is constant. The peak 
state stress ratio decreases with increasing $b$ value, suggesting that the mobilized strength decreases under unit mean effective stress.

(4) The nonlinear strength envelopes of Mohr circles pass the origin in the $\sigma^{\prime}-\tau$ plane at different $b$ values, describing the coarse granular material as a typical cohesionless material well. For the tested material, the internal friction angle firstly increases with $b$ value from 0 to around 0.75 and then decreases slightly when $b$ value is close to unity.

(5) plane strain test is a simplified stress path test of an element in dam body and hence is meaningful. The peak strength obtained in the plane strain tests is close to that in constant $\sigma_{3}$ ' and constant $b$ tests when $b=0.25$. The slope of $\mathrm{q}: \mathrm{p}^{\prime}$ curve in the plane strain tests is greater than that in the constant $\sigma_{3}$ and constant $b$ tests.

(6) In the $\pi$ plane, Lade-Duncan strength envelope fits well with the peak strength of the coarse granular material with the maximum particle diameter of $60 \mathrm{~mm}$ obtained in the large-scale true triaxial tests. Lade-Duncan strength envelope shows obvious shrinkage feature under different confining pressures, implying the nonlinear feature of the actual strength envelope.

\section{Data Availability}

The data used to support the findings of this study are available from the corresponding author upon request.

\section{Conflicts of Interest}

The authors declare they have no conflicts of interest regarding the publication of this paper.

\section{Acknowledgments}

This work was supported by the National Natural Science Foundation Projects of China (Grant Nos. 51979010 and U1765203), and the Basic Scientific Research Grant of Natural Public Academies and Institutes (Grant no. CKSF2019182/YT).

\section{References}

[1] Y. Xiao, Y. Sun, H. Liu, and F. Yin, "Critical state behaviors of a coarse granular soil under generalized stress conditions," Granular Matter, vol. 18, p. 17, 2016.

[2] Q. Xu, W. Chen, and H. Jin, "Characteristics and distribution of thick overburdens along the Dadu river valley," Quaternary Sciences, vol. 30, no. 1, pp. 30-36, 2010.

[3] Japanese Society of soil mechanics and Engineering, Field Compaction of Coarse Granular Material, Japanese Society of soil mechanics and Engineering, Tokyo, Japan, 1990.

[4] P. V. Lade and Q. Wang, "Analysis of shear banding in true triaxial tests on sand," Journal of Engineering Mechanics, vol. 127, no. 8, pp. 762-768, 2001.

[5] H. Matsuoka and T. Nakai, "Stress-deformation and strength characteristics of soil under three different principal stresses,"
Proceedings of Japan Society Civil Engineers, vol. 232, pp. 59-70, 1974.

[6] B. X. Yuan, M. Sun, Y. X. Wang et al., "Full 3D displacement measuring system for 3D displacement field of soil around a laterally loaded pile in transparent soil," International Journal of Geomechanics, vol. 19, no. 5, Article ID 04019028, 2019.

[7] B. X. Yuan, M. Sun, L. Xiong et al., "Investigation of 3D deformation of transparent soil around a laterally loaded pile based on a hydraulic gradient model test," Journal of Building Engineering, vol. 28, no. 3, Article ID 101024, 2020.

[8] W. Kjellman, "Report on an apparatus for consumate investigation of the mechanical properties of soils," in Proceedings of the Proceedings of the 1st International Conference on Soil Mechanics and Foundation Engineering, Cambridge, MA, USA, June 1936.

[9] E. C. Hambly, "A new true triaxial apparatus," Geotechnique, vol. 19, no. 2, pp. 307-309, 1969.

[10] H. Matsuoka, D. A. Sun, and A. Kogane, "Stress-strain behaviour of unsaturated soil in true triaxial tests," Canadian Geotechnical Journal, vol. 39, pp. 608-619, 2002.

[11] K. R. Reddy, S. K. Saxena, and J. S. Budiman, "Development of a true triaxial testing apparatus," Geotechnical Testing Journal, vol. 15, no. 2, pp. 89-105, 1992.

[12] D. Mandeville and D. Penumadu, "True triaxial testing system for clay with proportional-integral-differential (PID) control," Geotechnical Testing Journal, vol. 27, no. 2, pp. 1-11, 2004.

[13] C. Choi, P. Arduino, and M. D. Harney, "Development of a true triaxial apparatus for sands and gravels," Geotechnical Testing Journal, vol. 31, no. 1, pp. 1-13, 2008.

[14] P. Hu, M. S. Huang, and S. K. Ma, "True triaxial tests and strength characteristics of silty sand," Rock and Soil Mechanics, vol. 32, no. 2, pp. 465-470, 2011.

[15] G. E. Green, "Strength and compressibility of granular materials under generalized strain conditions," $\mathrm{Ph}$. D. thesis, University of London, London, UK, 1969.

[16] K. A. Alshibli and H. S. Williams, "A true triaxial apparatus for soil testing with mixed boundary conditions," Geotechnical Testing Journal, vol. 28, no. 6, pp. 534-543, 2005.

[17] L. Q. Anhdan, J. Koseki, and T. Sato, "Evaluation of quasielastic properties of gravel using a large-scale true triaxial apparatus," Geotechnical Testing Journal, vol. 29, no. 5, pp. 374-384, 2006.

[18] J. H. Yin, W. H. Zhou, M. Kumruzzaman et al., "A rigidflexible boundary true triaxial apparatus for testing soils in a three-dimensional stress state[J]," Geotechnical Testing Journal, vol. 34, no. 3, pp. 1-8, 2011.

[19] C. L. Chen, S. J. Shao, and A. Z. Luo, "True triaxial tests on structural effects on strength of intact loess," Chinese Journal of Geotechnical Engineering, vol. 35, no. 12, pp. 2322-2327, 2013.

[20] G. L. Ye, B. Ye, and F. Zhang, "Strength and dilatancy of overconsolidated clays in drained true triaxial tests," J. Geotech. Geoenviron. Eng.vol. 140, no. 4, Article ID 06013006, 2014.

[21] P. V. Lade and J. M. Duncan, "Elastoplastic stress-strain theory for cohesionless soil," Journal of Geotechnical Engineering Division, vol. 101, no. 10, pp. 1037-1053, 1975.

[22] P. V. Lade, "Failure criterion for frictional materials," in Mechanics of Engineering Materials, C. S. Desai and R. H. Gallagher, Eds., pp. 385-402, John Wiley \& Sons, Hoboken, NJ, USA, 1984.

[23] A. Jaiswal and B. K. Shrivastva, "A generalized three-dimensional failure criterion for rock masses," Journal of Rock 
Mechanics and Geotechnical Engineering, vol. 4, pp. 333-343, 2012.

[24] D. A. Sun, W. X. Huang, and Y. P. Yao, “An experimental study of failure and softening in sand under three-dimensional stress condition," Granular Matter, vol. 10, no. 3, pp. 187-195, 2008.

[25] W. Shi, J. Zhu, G. Dai, and X. Li, "True triaxial tests of coarsegrained soil on $\pi$-plane and its strength criterion," Journal of Hohai University( Natural Sciences), vol. 43, no. 1, pp. 11-15, 2015.

[26] Y. Xiao, H. Liu, Y. Sun et al., "Stress-dilatancy behaviors of coarse granular soils in three-dimensional stress space," Engineering Geology, vol. 195, no. 1, pp. 104-110, 2015.

[27] The National Standards Compilation Group of China, Specification on Soil Testing SL237-1999, China Water and Power Press, Beijing, China, 1999.

[28] The Upstream of Jinshajiang River Development Corporation, Ground Investigation Report on the Overburden Layer of the Dam Site, Jinsha River Upstream Hydropower Development Company, Jinsha River, China, 2016.

[29] Z. Cheng, Y. Wang, and X. Rao, "A loading plate with low friction in geotechnical true triaxial apparatus," Patent No. ZL 201520613876, 2015.

[30] J. M. Duncan, P. M. Byrne, and K. S. Wong, Strength, StressStrain and Bulk Modulus Parameters for Finite Element Analysis of Stresses and Movements in Soil Masses, Berkeley University of Calufornia, Berkeley, CA, USA, 1980.

[31] M. U. Ergun, "Evaluation of three-dimensional shear testing," in Proceedings of the 10th International Conference on Soil Mechanics and Foundation Engineering, pp. 593-596, Stockholm, Sweden, May 1981.

[32] D. W. Reades and G. E. Green, "Independent stress control and triaxial extension tests on sand," Géotechnique, vol. 26, no. 4, pp. 551-576, 1976. 